\title{
Attenuated Salmonella choleraesuis-mediated RNAi targeted to conserved regions against foot-and-mouth disease virus in guinea pigs and swine
}

\author{
Wei ConG ${ }^{1}$, Hong $\mathrm{J}_{\mathrm{IN}}{ }^{1}$, Chengda $\mathrm{J}_{\mathrm{IANG}}{ }^{1}$, Weiyao $\mathrm{YAN}^{1}$, Mingqiu LiU ${ }^{1}$, \\ Jiulian $\mathrm{CHEN}^{2}$, Xiaoping ZuO ${ }^{2}$, Zhaoxin ZHENG ${ }^{1 *}$ \\ ${ }^{1}$ State Key Laboratory of Genetic Engineering, Institute of Genetics, School of Life Science, Fudan University, \\ 220 Handan Rd., Shanghai 200433, People's Republic of China \\ ${ }^{2}$ Bio-pharmacy, Jinyu Group Co., Ltd., Inner Mongolia 010020, People's Republic of China
}

(Received 21 April 2009; accepted 11 January 2010)

\begin{abstract}
In this study, specific sequences within three genes (3D, VP4 and 2B) of the foot-and-mouth disease virus (FMDV) genome were determined to be effective RNAi targets. These sequences are highly conserved among different serotype viruses based on sequence analysis. Small interfering RNA (siRNA)expressing plasmids (p3D-NT19, p3D-NT56, pVP4-NT19, pVP4-NT65 and p2B-NT25) were constructed to express siRNA targeting 3D, VP4 and 2B, respectively. The antiviral potential of these siRNA for various FMDV isolates was investigated in baby hamster kidney (BHK-21) cells and suckling mice. The results show that these siRNA inhibited virus yield 10- to 300-fold for different FMDV isolates of serotype $\mathrm{O}$ and serotype Asia I at $48 \mathrm{~h}$ post infection in BHK-21 cells compared to control cells. In suckling mice, p3DNT56 and p2B-NT25 delayed the death of mice. Twenty percent to $40 \%$ of the animals that received a single siRNA dose survived 5 days post infection with serotype O or serotype Asia I. We used an attenuated Salmonella choleraesuis (C500) vaccine strain, to carry the plasmid that expresses siRNA directed against the polymerase gene 3D (p3D-NT56) of FMDV. We used guinea pigs to evaluate the inhibitory effects of recombinant $S$. cho (p3D-NT56/S. cho) on FMDV infection. The results show that $80 \%$ of guinea pigs inoculated with $10^{9} \mathrm{CFU}$ of p3D-NT56/S. cho and challenged $36 \mathrm{~h}$ later with $50 \mathrm{ID}_{50}$ of homologous FMDV were protected. We also measured the antiviral activity of p3D-NT56/S. cho in swine. The results indicate that $100 \%$ of the animals treated with $5 \times 10^{9} \mathrm{CFU}$ of $\mathrm{p} 3 \mathrm{D}-\mathrm{NT} 56 / \mathrm{S}$. cho were protected in 9 days.
\end{abstract}

foot-and-mouth disease virus / RNA interference / Salmonella choleraesuis / conserved sequence / swine

\section{INTRODUCTION}

Short interfering RNA (siRNA) are small, double-stranded RNA molecules that direct the degradation of complementary messenger RNA via a cellular process known as RNA interference. It is widely believed that RNA interference is an evolutionarily conserved

\footnotetext{
* Corresponding author: zxzheng@fudan.edu.cn
}

mechanism within eukaryotes and that its functions include endogenous gene regulation, viral defense and the maintenance of genomic stability [14]. Because of the rapidity and specificity of RNAi, this technology could complement and improve the traditional tools available to control important animal pathogens.

Foot-and-mouth disease (FMD) is an extremely contagious disease that affects more than 33 species of cloven-hoofed animals including

This is an Open Access article distributed under the terms of the Creative Commons Attribution-Noncommercial License (http://creativecommons.org/licenses/by-nc/3.0/), which permits unrestricted use, distribution, and reproduction in any noncommercial medium, provided the original work is properly cited. 
cattle, swine, and other livestock [36]. The disease has been known for five centuries and its causative agent, the FMD virus (FMDV), belongs to the genus Aphthovirus of the family Picornaviridae [1]. The FMDV genome is composed of a positive-sense, single-stranded RNA molecule of about 8500 nucleotides that contains a unique open reading frame. Like other RNA viruses, FMDV is antigenically variable and undergoes rapid mutation. There are seven distinguishable serological types of FMDV, namely O, A, C, Asia I, SAT1, SAT2, and SAT3. Current FMD vaccines based on inactivated virus are effective in preventing the disease, but carry the risks of incomplete inactivation and viral escape from vaccine production laboratories [26], and they fail to induce an immune response in a short period. Thus, the development of emergency antiviral strategies is necessary in order to stem outbreaks of FMD.

As an antiviral technology, RNAi has already been widely researched for use with FMDV [5, 24, 33]. However, establishing RNAi as a viable approach to prevent FMDV requires resolving at least one major issue $[17,20]$ : the high genetic variability of FMD viruses. RNAi directed toward specific gene sequences of certain FMDV strains may face risks, especially in the event of an emergent FMD outbreak, because no information about the serotype or genotype of the isolated pathogen would be available while early protection is needed. Therefore, it may be necessary to design several siRNA that focus on the conserved regions of the viral genome $[16,17,42,46]$. Previously, we showed that siRNA generated in vitro can effectively inhibit the replication of FMDV in either a specific or cross-inhibitory manner [28]. Another crucial issue that needs to be addressed is the optimal vector for delivery of siRNA-expressing cassettes. Chen et al. [6] demonstrated that treatment with recombinant, replication-defective human adenovirus type 5 expressing short-hairpin RNA significantly reduces the susceptibility of guinea pigs and swine to FMDV infection. However, adenovirus VA1 non-coding RNA is able to inhibit the biogenesis of siRNA and microRNA [30]. This finding suggests that novel siRNA delivery systems would be necessary.
Salmonella, a member of enteric bacilli, is one of the most severe etiological agents of food-borne diseases. It is widely accepted that recombinant live vaccines using attenuated Salmonella as a vector to deliver passenger antigen induce immune responses not only against salmonella infection, but also against passenger pathogenic infection [8]. Live-attenuated Salmonella has been shown to deliver DNA vaccines [9, 35, 41, 47]. Early in the 1970s, Fang et al. screened out an attenuated Salmonella choleraesuis C500, which was a licensed live vaccine against swine paratyphoid [13]. Liu et al. proved that the attenuated $S$. choleraesuis C500 carrying an oral DNA vaccine induced an immune response against FMDV [29].

In the present study, we constructed several siRNA-expressing plasmids targeted to conserved sequences within the coding regions of viral polymerase protein $3 \mathrm{D}$, capsid protein VP4 and nonstructural (NP) protein 2B of the FMDV genome. Some of the plasmids inhibited several isolates of serotype $\mathrm{O}$ and serotype Asia I FMDV in baby hamster kidney (BHK21) cells and suckling mice. Furthermore, we reported that siRNA directed against the polymerase protein 3D of FMDV and delivered by attenuated $S$. choleraesuis were capable of inhibiting virus replication in guinea pigs and swine.

\section{MATERIALS AND METHODS}

\subsection{Bacteria and plasmids}

The attenuated vaccine strain $S$. choleraesuis C500 was obtained from Nanjing Biological Pharmaceutical Co., Ltd. Attenuated Salmonella typhimurium LB5010 was kindly provided by Prof. Aoquan Wang (Institute of Microbiology, Chinese Academy of Sciences). The plasmid pU6, which has the mouse U6 promoter $\left(\mathrm{P}_{\mathrm{U}}\right)$, was constructed and maintained in our laboratory.

\subsection{Animals}

Suckling mice (C57BL/6), 2 to 3 days old and weighing 3 to $4 \mathrm{~g}$, were maintained by Bio-pharmacy, Jinyu Group Co., Ltd. Male and female guinea pigs weighing 250 to $300 \mathrm{~g}$ and large white swine, 
2- to 3-months-old and weighing 40 to $50 \mathrm{~kg}$, were used to perform viral challenge. All of the animals were housed in disease-secure isolation facilities in an FMDV-free area, and had no previous FMD contact as confirmed by the absence of detectable antiFMDV antibodies in their sera.

\subsection{Cells and viruses}

Human kidney cells (AD-293) were used to grow recombinant replication-defective human adenoviruses (rAd5) and determine virus titers. BHK-21 cells were used to grow FMDV and determine virus infectivity. Both of the cell lines were cultured in Dulbecco's modified Eagle's medium (DMEM) supplemented with $10 \%$ heat-inactivated fetal bovine serum $(\mathrm{pH}$ 7.4). Cultures were incubated at $37{ }^{\circ} \mathrm{C}$ with $5 \% \mathrm{CO}_{2}$. Two FMDV isolates of serotype $\mathrm{O}(\mathrm{HKN} / 2002$ (GenBank accession number AY317098) and CHA/ 99 (GenBank accession number AJ539138)) and two FMDV isolates of serotype Asia I (YNBS/58 (GenBank accession number AY390432) and Jiangsu/ 2005 (GenBank accession number EF149009)) were used for viral challenge.

Recombinant replication-defective human adenoviruses (Ad5-POL and Ad5-LacZ) were constructed and maintained in our laboratory [6]. Ad5-POL expressed siRNA targeting the FMDV 3D sequence corresponding to nucleotides (nt) 1225-1280 of $\mathrm{HNK} / 2002$ 3D. As a control for nonspecific effects of rAd5, Ad5-LacZ expressed siRNA corresponding to nt 1353 to 1435 of the $\beta$-galactosidase gene of Escherichia coli, which has no homology to the $\mathrm{HKN} / 2002$ genome as confirmed by sequence analysis. The sequence of Ad5-POL encoding the FMDV 3D-specific siRNA was 5'-GAGGCTATCCTCTC CTTTGCACGCCGTGGGACCATACAGGAGAAG TTGATCTCCGT-3' (sense), and that of Ad5-LacZ encoding the $E$. coli $\beta$-galactosidase-specific siRNA was $5^{\prime}$-GAGTGTGATCATCTGGTCGCTGGGGA ATGAATCAGGCCACGGCGCTAATCACGACGC GCTGTATCGCTGGATCAAATCTGTCG-3' (sense).

\subsection{Construction of siRNA-expressing plasmids}

As a general strategy for constructing siRNAexpressing plasmids, inverted repeats targeting the sequence were cloned into plasmid pU6 at the EcoRI/HindIII sites, under the control of the U6 promoter and the termination signals of 4 or 5 thymidines. Plasmids p3D-NT19, p3D-NT56, pVP4NT19, pVP4-NT65 and p2B-NT25 contained inverted repeats corresponding to the nucleotide sequences of the FMDV genome, as described below.
As negative controls for nonspecific effects, plasmid pNTH21 and pLacZ contained inverted repeats of $21 \mathrm{nt}$ and $83 \mathrm{nt}$, respectively, which have no homology to the FMDV genome, as confirmed by sequence analysis.

The targets of interest were essential during the life cycle of FMDV and relatively conserved in their nucleotide sequences. The reference sequences of the conserved regions of the FMDV genome were obtained from the National Center for Biotechnology Information (NCBI) website $^{1}$ and compared by nucleotide (nt) BLAST. The sequence of 3D-NT19 was 5'-GTTCTTGGTCACTCCATAA-3', corresponding to nt $1123-1141$ of the HKN/2002 $3 \mathrm{D}$ gene; the sequence of 3D-NT56 was $5^{\prime}$-GAG GCTATCCTCTCCTTTGCACGCCGTGGGACCAT ACAGGAGAAGTTGATCTCCGT-3', corresponding to nt 1225-1280 of the HKN/2002 3D gene; the sequence of VP4-NT65 was 5'-TCAGGCAA CACTGGAAGCATCATTAACAACTACTACATGC AGCAGTACCAGAACTCCATGGACAC-3', corresponding to nt 43-107 of the YNBS/58 VP4 gene; the sequence of VP4-NT19 was 5'-ACAACTACTA CATGCAGCA-3' ${ }^{\prime}$, corresponding to nt $68-86$ of the YNBS/58 VP4 gene; the sequence of 2B-NT25 was $5^{\prime}$-CCAGATGCAGGAGGACATGTCAACA-3', corresponding to nt $57-81$ of the CHA/99 2B gene.

\subsection{Cell transfection and viral challenge assays}

Virus infectivity was determined by serial dilution of the sample on BHK-21 cells grown in 96-well plates and the virus titer was calculated as a tissue culture infective dose by the Reed-Muench method [38]. A viral suspension titrated at $10^{5}$ to $10^{7} \mathrm{TCID}_{50}$ per $0.1 \mathrm{~mL}$ was used for viral challenge. BHK-21 cells were seeded in 96-well plates in DMEM $24 \mathrm{~h}$ before transfection. The cells (about 95\% confluent) were transiently transfected with $0.1 \mu \mathrm{g}$ of a single plasmid expressing 3D, VP4 or $2 \mathrm{~B}$ specific siRNA. Five hours after transfection, the transfection complex was removed, cells were washed twice with DMEM, and $100 \mathrm{TCID}_{50}$ of FMDV per $0.1 \mathrm{~mL}$ was added to each well. After $1 \mathrm{~h}$ of adsorption, the inoculum was removed and cells were washed twice with DMEM. The infection then proceeded in DMEM supplemented with $10 \%$ fetal bovine serum. Cell supernatants were collected at designated time points, and the virus titers were determined three times on BHK-21 cells. Statistical analysis was performed with the Microsoft Excel program (Microsoft, Redmond, WA, USA).

\footnotetext{
${ }^{1}$ www.ncbi.nlm.nih.gov
} 


\subsection{Viral challenge assay in suckling mice}

Suckling mice ( 8 groups of 20 each) were subcutaneously injected in the neck with $100 \mu \mathrm{g}$ of plasmids in $100 \mu \mathrm{L}$ of phosphate-buffered saline (PBS). After $6 \mathrm{~h}$, the suckling mice were challenged with $20 \mathrm{LD}_{50}$ of FMDV per $0.1 \mathrm{~mL}$ via subcutaneous injection into the neck near the site that received the injected DNA. The mice were then observed for 5 days post-challenge (dpc). Statistical analysis was performed with a log rank test ${ }^{2}$.

\subsection{Construction and identification of recombinant attenuated $S$. choleraesuis}

In order to prepare the recombinants (p3D-NT19/ S. cho, pLacZ/S. cho and p3D-NT56/S. cho), the attenuated $S$. typhimurium LB5010, an intermediate host cell, was first transformed with plasmids (pLacZ, p3D-NT56 and p3D-NT19) using a standard $\mathrm{CaCl}_{2}$ method. Then, the plasmids were extracted and transferred to a terminal host cell-attenuated $S$. choleraesuis C500 by electroporation. The preparation of cells for electroporation was as follows: C500 cells were cultured in $3 \mathrm{~mL} \mathrm{LB}$ medium at $200 \mathrm{rpm}$ overnight at $37{ }^{\circ} \mathrm{C}$, and then were inoculated into $25 \mathrm{~mL}$ liquid $\mathrm{LB}$ medium at $1 \%(\mathrm{v} / \mathrm{v})$ at $37{ }^{\circ} \mathrm{C}$, again with shaking at $200 \mathrm{rpm}$. Bacteria were grown to an optical density (OD) of $0.6-0.7$, chilled and then collected by centrifugation at $4000 \mathrm{rpm}$ for $10 \mathrm{~min}$ at $4{ }^{\circ} \mathrm{C}$. The cells were then washed with $10 \%$ glycerol three times. The cells were re-suspended in $10 \%$ glycerol at a concentration of $3 \times 10^{10}$ cells $/ \mathrm{mL}$, frozen in dry ice, and stored at $-70{ }^{\circ} \mathrm{C}$. A $200 \mu \mathrm{L}$ aliquot of the cells was thawed and used for transformation. One microgram DNA (the control setup with no DNA) was mixed with cold cell suspension and then transferred to a chilled cuvette. Transformation was carried out with a Bio-Rad Gene Pulser at $2.0 \mathrm{kV}, 25 \mu \mathrm{F}, 200 \Omega$ at $0-4{ }^{\circ} \mathrm{C}$. Transformed competent cells were transferred to a tube, and $400 \mu \mathrm{L}$ of media were added prior to incubating the cultures for $1.5 \mathrm{~h}$ at $50 \mathrm{rpm}$ at $37{ }^{\circ} \mathrm{C}$. Then, $80 \mu \mathrm{L}$ of the cultures were transferred onto solid LB medium containing $100 \mu \mathrm{L} / \mathrm{mL}$ ampicillin. Recombinant bacteria were identified via PCR. The presence of the recombinant plasmid was confirmed by digestion with XhoI. Serological characteristics of recombinant $S$. choleraesuis (rS. cho) were tested using a congregation reaction on a glass plate to confirm its immunogenicity.

\footnotetext{
$\overline{2}$ http://bioinf.wehi.edu.au/software/russell/logrank/
}

\subsection{Viral challenge in guinea pigs and swine}

Live bacteria were prepared by culturing cells in $25 \mathrm{~mL}$ liquid $\mathrm{LB}$ medium at $37^{\circ} \mathrm{C}$ for $18 \mathrm{~h}$ followed by inoculation of $2.5 \mathrm{~mL}$ cultures into $25 \mathrm{~mL}$ liquid $\mathrm{LB}$ medium to produce $2 \times 10^{9}$ $5 \times 10^{9} \mathrm{CFU} / \mathrm{mL}$. Live bacteria counting was performed by serial dilution of cultures followed by spread plating. Serotype O FMDV strain HKN/ 2002 passaged five times in suckling mice was used to challenge guinea pigs, and the virus passaged three times in swine was used for swine experiments. The viruses were titrated on guinea pigs and swine. The dose of FMDV used was determined through four 10 -fold serial dilutions of virus (i.e. $10^{-4}, 10^{-5}, 10^{-6}$, and $10^{-7}$ ) in PBS. Guinea pigs (4 groups of 6 animals each) were inoculated intradermally in the left rear foot with $0.1 \mathrm{~mL}$ of serially diluted viruses. According to the method described by Chen et al. [6], the swine (4 groups of 4 each) were inoculated in the neck region by intramuscular injection of each animal with $2 \mathrm{~mL}$ of serially diluted virus. All of the animals were then monitored for the major clinical sign of FMD, the appearance of vesicles on the mouth or feet. The $50 \%$ animal infective dose $\left(\mathrm{ID}_{50}\right)$ was estimated using the Reed-Muench method [38]. Statistical analysis was performed with a log rank test ${ }^{2}$.

\subsubsection{Guinea pig experiment 1}

Guinea pigs in several groups of five each were inoculated by intramuscular injection with $1.0 \times 10^{9} \mathrm{CFU}$ of recombinant attenuated $S$. choleraesuis in $0.1 \mathrm{~mL}$ of saline. Thirty-six hours after inoculation, FMDV challenge was carried out via intradermal injection of each animal with $0.1 \mathrm{~mL}$ of guinea pig infectious dose $50 \mathrm{ID}_{50}$ of $\mathrm{HKN} / 2002$ in the left rear foot, as was done for virus titration.

\subsubsection{Guinea pig experiment 2}

In a parallel experiment, animals were treated with $1.0 \times 10^{6} \mathrm{PFU}$ of rAd5 and challenged $36 \mathrm{~h}$ later with $50 \mathrm{ID}_{50}$ of $\mathrm{HKN} / 2002$. To test whether the combined inoculations of rAd5 and $\mathrm{rS}$. cho protected animals, some groups were injected intramuscularly with the p3D-NT56/S. cho+Ad5-POL mixture of $1.0 \times 10^{9} \mathrm{CFU}$ and $1.0 \times 10^{6} \mathrm{PFU}$, respectively; then, after $36 \mathrm{~h}$, they were challenged with $50 \mathrm{ID}_{50}$ of $\mathrm{HKN} / 2002$. 


\subsubsection{Swine experiment}

Eighteen swine were divided into 5 groups of 3 or 4 animals each. The animals in each group were cohoused in a separate room. All groups were inoculated via intramuscular injection in the neck area. Group 1 was a mock control group inoculated with $2 \mathrm{~mL}$ of saline. As negative controls, groups 2 and 3 were inoculated with $5 \times 10^{9} \mathrm{CFU}$ of $S$. choleraesuis $\mathrm{C} 500$ or LacZ/S. cho in $2 \mathrm{~mL}$ of saline, respectively. Group 4 was inoculated with $5 \times 10^{9} \mathrm{CFU}$ of p3D-NT56/S. cho in $2 \mathrm{~mL}$ of saline. Group 5 was treated with a high dose of $\mathrm{p3D}-\mathrm{NT} 56 / S$. cho containing $5 \times 10^{10} \mathrm{CFU}$ in $2 \mathrm{~mL}$ of saline. After $24 \mathrm{~h}$, all animals were challenged via intramuscular injection with $100 \mathrm{ID}_{50}$ of $\mathrm{HKN} / 2002$ in $2 \mathrm{~mL}$ of PBS in the neck area. To avoid overexposure to the challenge virus, animals that developed disease were moved to another room, and then observation proceeded. After challenge, the animals were examined daily for clinical signs of FMD, including an increase in body temperature (above $40{ }^{\circ} \mathrm{C}$ ) and the appearance of vesicles on the mouth and feet. The lesion score was determined at various time points post-challenge by determining the number of digits plus mouth with vesicles for each animal. The observations were terminated on day 14 post-challenge, when the animals were humanely killed.

\subsection{Serological analysis}

Blood and serum samples were collected at days 7 and 14 after challenge in swine experiments. To assess the neutralizing antibody response in the swine, plaque reduction neutralization assays were performed as described previously [31]. Neutralizing titers were reported as the highest serum dilution causing a $50 \%$ reduction in the number of HKN/ 2002 plaques on BHK-21 cells. The presence of antibodies against viral NS protein $3 \mathrm{ABC}$ of FMDV in the sera was detected using a solid-phase blocking enzyme-linked immunosorbent assay (SPB-ELISA) according to the procedures described by Chenard et al. [7]. Briefly, ELISA microtiter test plates were coated overnight at $4{ }^{\circ} \mathrm{C}$ with recombinant $3 \mathrm{ABC}$ antigen expressed in E. coli [45]. After five washes with PBS containing $0.05 \%$ Tween 80 (PBST), each well of the plates was filled with $100 \mu \mathrm{L}$ of test or reference serum diluted 1:2 in PBST and incubated at $37{ }^{\circ} \mathrm{C}$ for $60 \mathrm{~min}$. The serum was then removed, and the wells of the plates were washed as described above. After rewashing, $100 \mu \mathrm{L}$ of anti-3ABC immunoglobulin-horseradish peroxidase conjugate was added, and the incubation proceeded at $37^{\circ} \mathrm{C}$ for $30 \mathrm{~min}$. The conjugate was then removed, the wells of the plates were washed again, and $100 \mu \mathrm{L}$ of a commercially ready-to-use tetramethyl benzidine chromogen substrate was added to the plates. After incubation at $37{ }^{\circ} \mathrm{C}$ for $10 \mathrm{~min}$, the reaction was stopped by adding $50 \mu \mathrm{L}$ of $2.0 \mathrm{M} \mathrm{H}_{2} \mathrm{SO}_{4}$ per well, and the OD at $450 \mathrm{~nm}$ was measured by using an ELISA reader. The sera were considered positive if the OD was reduced by $\geq 30 \%$ compared to a standard negative serum corrected for background signal by subtracting the OD of the high positive reference serum. Statistical analysis was performed with the Microsoft Excel program.

\section{RESULTS}

\subsection{FMDV-specific siRNA-expressing plasmids induced antiviral effects to different isolates of serotype $O$ and serotype Asia I FMDV in BHK-21 cells}

To test the antiviral activity of siRNA, BHK-21 cells cultured in 96-well plates were transfected with siRNA-expressing plasmids individually. As controls, the cells were either not treated or treated with plasmid pNTH21 or pLacZ. After $24 \mathrm{~h}$, the cells were infected with $100 \mathrm{TCID}_{50}$ of CHA/99, HNK/2002, YNBS/ 58 or Jiangsu/2005. The cells were observed continuously under the microscope. Microscopy examination revealed that the cells treated with p3D-NT56 or p2B-NT25 had delayed cytopathic effect (CPE) development when challenged with either serotype $\mathrm{O}$ or Asia I of FMDV. However, the control cells, either blank or transfected with the control plasmids, showed an extensive CPE within $24 \mathrm{~h}$ post infection (p.i.).

Furthermore, we investigated the effect of plasmid-mediated RNAi on FMDV replication by measuring the $\mathrm{TCID}_{50}$ of supernatants of lysed cells, which were collected at 12, 24 and $48 \mathrm{~h}$ after viral challenge. Consistent with the observation, p3D-NT56 and p2B-NT25 showed a wider cross-inhibitory effect than the other plasmids, and these 2 plasmids inhibited 4 FMDV isolates (Fig. 1). The supernatant TCID $_{50}$ for CHA/99, HNK/2002, YNBS/58 and Jiangsu/2005 of the cells treated with p3D-NT56 or p2B-NT25 was reduced by 

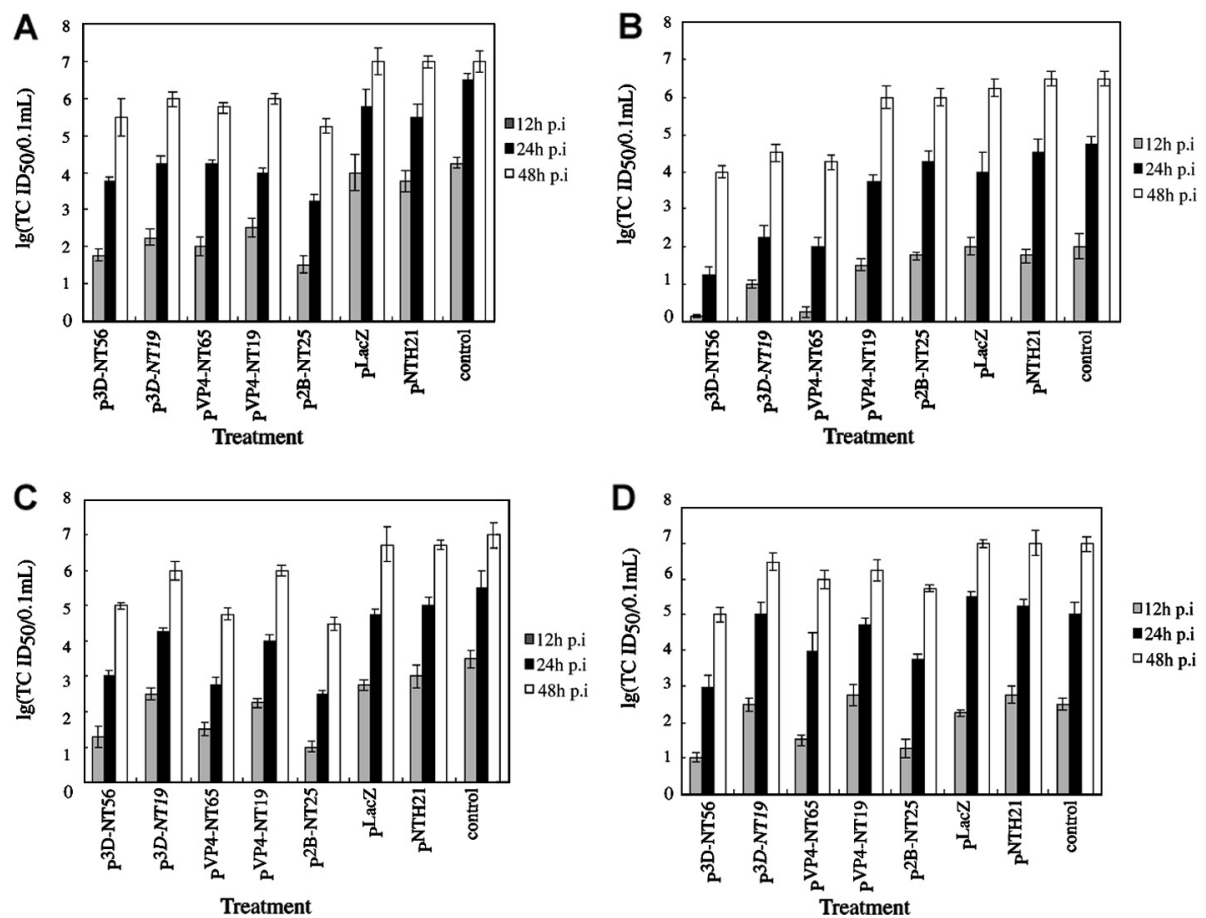

Figure 1. Decrease of virus yield in BHK-21 cells treated with siRNA-expressing plasmids. Cells transiently transfected with either control plasmids or specific siRNA-expressing plasmids were infected with $100 \mathrm{TCID}_{50}$ of FMDV HKN/2002 (A), FMDV CHA/99 (B), FMDV YNBS/58 (C) and FMDV Jiangsu/2005 (D) per $0.1 \mathrm{~mL}$. Culture supernatants were collected at different times, and the virus titer $\left(\mathrm{TCID}_{50}\right)$ was determined three times on BHK-21 cells. Error bars indicate standard deviations.

30- to 300 -fold at $48 \mathrm{~h}$ post infection (Fig. 1) compared to the control groups.

\subsection{Treatment with siRNA-expressing plasmids conferred resistance against FMDV in suckling mice}

To further examine the anti-FMDV potential of p3D-NT56 or p2B-NT25 in vivo, we challenged suckling mice pretreated by subcutaneous injection of plasmids with FMDV strains $\mathrm{HKN} / 2002$ or $\mathrm{YNBS} / 58$. All PBS-treated mice died within $60 \mathrm{~h}$ after either $\mathrm{HNK} / 2002$ or YNBS/58 challenge (Fig. 2). The animals treated with control plasmids were also not protected at all, although death in some groups was delayed slightly $(p=0.47, p=0.157)$ (Fig. 2). In HKN/2002 challenge experiments,
$20 \%$ of the animals treated with either p3DNT56 or p2B-NT25 were protected (Fig. 2A). The difference between the survival of mice treated with either p3D-NT56 or p2B-NT25 and the PBS control was statistically significant $(p<0.0001)$. In the case of challenge with YNBS/58, 8 of 20 mice treated with p3DNT56 and 7 of 20 mice treated with p2BNT25 survived a viral challenge of $20 \mathrm{LD}_{50}$ (Fig. 2B), and a significant difference in mouse survival was seen between mice treated with either p3D-NT56 or p2B-NT25 and controls $(p<0.0001)$. Furthermore, in both HNK/2002 and $\mathrm{YNBS} / 58$ challenge assays, the time of $50 \%$ death of mice was delayed for 9 to $24 \mathrm{~h}$ in groups treated with FMDV-specific siRNAexpressing plasmids as compared with control groups. 

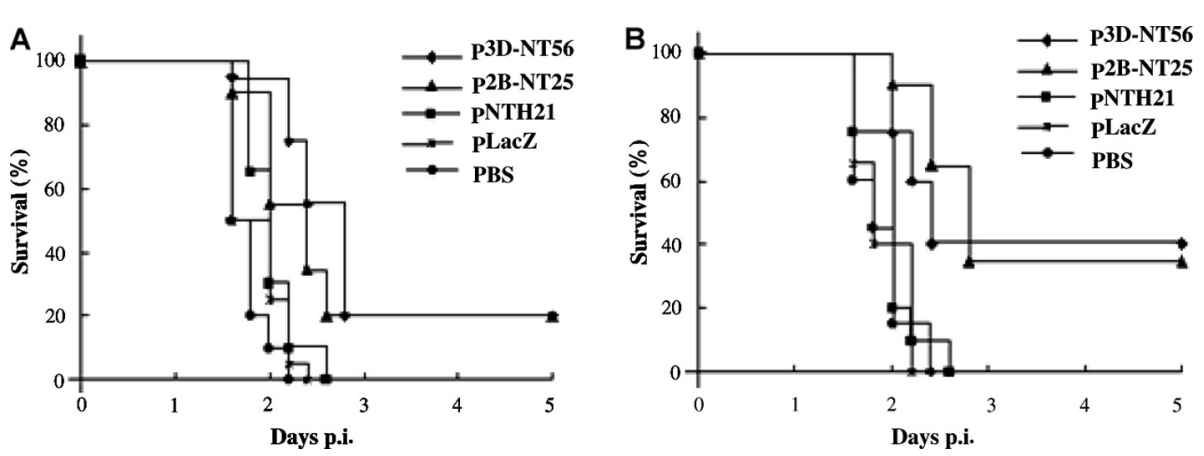

Figure 2. siRNA synthesized in vivo induce antiviral response in suckling mice and promote survival after FMDV infection. Suckling mice were challenged by subcutaneous injection in the neck with $20 \mathrm{LD}_{50}$ of $\mathrm{HKN} / 2002$ (A) or $20 \mathrm{LD}_{50}$ of YNBS/58 (B) after $6 \mathrm{~h}$ of treatment with either control plasmids or FMDVspecific siRNA-expressing plasmids. All animals were observed for 6 days after challenge.

\subsection{FMDV-specific rS. cho constructs inhibited virus infection in guinea pigs}

The data obtained in the cell culture and suckling mice assays demonstrated that siRNA targeted to conserved regions of the FMDV genome could be effective against FMDV in either a specific or a cross-inhibitory manner. The potential of RNAi as an antiviral strategy against FMDV in relevant animal systems is of great interest. The fact that attenuated Salmonella is widely used as a DNA vaccine vector made us choose it as the vector for siRNA delivery. To test the anti-FMDV potential of rS. cho, we challenged guinea pigs pretreated by intramuscular injection of $\mathrm{r} S$. cho constructs with FMDV HKN/2002. All saline-treated animals developed the major clinical sign of FMD, the appearance of vesicles on the feet, within $48 \mathrm{~h}$ of challenge (Tab. I). Guinea pigs treated with $\mathrm{pLacZ} / S$. cho were not protected at all, though the clinical signs were delayed in some animals, as shown in Table I. However, 4 of 5 guinea pigs pretreated with $10^{9} \mathrm{CFU}$ of $\mathrm{p} 3 \mathrm{D}-\mathrm{NT} 56 / S$. cho and challenged with $50 \mathrm{ID}_{50}$ of $\mathrm{HKN} / 2002$ developed none of the clinical signs such as vesicles or high fever. These results indicated that $S$. cho-delivered siRNA exerted in vivo inhibitory activity against FMDV in guinea pigs.

We further evaluated the potential of treatments with an FMDV-specific $\mathrm{r} S$. cho and rAd5 mixture in guinea pigs. Three of the five animals in the group treated with the p3DNT56/S. cho+Ad5-POL mixture were completely protected as determined by the absence of vesicles on their feet (Tab. I). No significant increase in antiviral effect was achieved in this group when compared to the group treated with p3D-NT56/S. cho alone (Tab. I). This indicated that a simple combination of two vectors could not improve the protection of animals.

\subsection{Treatment with p3D-NT56/S. cho confers significant resistance against FMDV infection in swine}

Based on the experiments in guinea pigs, we evaluated the antiviral activity of p3D-NT56/S. cho in swine. Animals were intramuscularly inoculated with $5 \times 10^{9} \mathrm{CFU}$ of p3D-NT56/S. cho and challenged $24 \mathrm{~h}$ later with $100 \mathrm{ID}_{50}$ of HKN/2002. All of the saline-treated swine developed acute signs of FMD, including vesicles and fever (Fig. 3A). Animal 1-48 had vesicles as early as $3 \mathrm{dpc}$, and its symptoms were extraordinarily severe. In comparison with this group, animals inoculated with either pLacZ/ $S$. cho or $S$. cho showed no signs of significant antiviral activity (Figs. 3B and 3C). However, p3D-NT56/S. cho conferred marked antiviral activity that could be seen for more than 9 days of observation (Fig. 3D). Animal 2-7 in this group developed a fever but no vesicles during the observation period. Although animals 5-6, 
Table I. Treatment with FMDV-specific rS. cho or a mixture of rS. cho and rAd5 inhibits FMDV HKN/2002 infection in guinea pigs ${ }^{\mathrm{a}}$.

\begin{tabular}{|c|c|c|c|c|c|c|c|c|c|}
\hline \multirow[t]{2}{*}{ Group } & \multirow{2}{*}{$\begin{array}{c}\text { Treatment } \\
(\mathrm{CFU} \text { or PFU })^{\mathrm{b}}\end{array}$} & \multicolumn{7}{|c|}{ No. protected/no. challenged for $\mathrm{dpc}$} & \multirow[t]{2}{*}{$p^{\mathrm{c}}$} \\
\hline & & 1 & 2 & 3 & 4 & 5 & 6 & 14 & \\
\hline Saline & & $3 / 5$ & $0 / 5$ & - & - & - & - & - & $\mathrm{AC}$ \\
\hline $\mathrm{pLacZ} / S$. cho & $10^{9}$ & $4 / 5$ & $1 / 5$ & $0 / 5$ & - & - & - & - & 0.308 \\
\hline p3D-NT56/S. cho & $10^{9}$ & $5 / 5$ & $5 / 5$ & $4 / 5$ & - & - & - & - & 0.00313 \\
\hline p3D-NT19/S. cho & $10^{9}$ & $5 / 5$ & $2 / 5$ & - & - & - & - & - & 0.0571 \\
\hline S. cho & $10^{9}$ & $1 / 5$ & $1 / 5$ & $0 / 5$ & - & - & - & - & 0.787 \\
\hline $\mathrm{pLacZ} / S$. cho & $10^{8}$ & $4 / 5$ & $0 / 5$ & - & - & - & - & - & 0.513 \\
\hline p3D-NT56/S. cho & $10^{8}$ & $5 / 5$ & $3 / 5$ & $2 / 5$ & $2 / 5$ & $1 / 5$ & - & - & 0.029 \\
\hline $\mathrm{pLacZ} / S$. cho & $10^{10}$ & $5 / 5$ & $1 / 5$ & $1 / 5$ & $0 / 5$ & - & - & - & 0.0951 \\
\hline p3D-NT56/S. cho & $10^{10}$ & $5 / 5$ & $4 / 5$ & $2 / 5$ & $2 / 5$ & $1 / 5$ & - & - & 0.0116 \\
\hline Ad5-LacZ+pLacZ/S. cho & $10^{6}+10^{9}$ & $2 / 5$ & $0 / 5$ & - & - & - & - & - & 0.549 \\
\hline Ad5-POL+p3D-NT56/S. cho & $10^{6}+10^{9}$ & $5 / 5$ & $3 / 5$ & - & - & - & - & - & 0.029 \\
\hline Ad5-LacZ & $10^{6}$ & $3 / 5$ & $1 / 5$ & $1 / 5$ & $0 / 5$ & - & - & - & 0.602 \\
\hline Ad5-POL & $10^{6}$ & $5 / 5$ & $5 / 5$ & $3 / 5$ & $2 / 5$ & - & - & - & 0.00313 \\
\hline
\end{tabular}

${ }^{a}-$ : Score is the same as the day before.

${ }^{\mathrm{b}} \mathrm{CFU}$ for $\mathrm{rS}$. cho and PFU for rAd5.

${ }^{\mathrm{c}}$ Statistical analysis by the log rank test.

Days post-challenge (dpc) and AC: as controls.

3-3 and 1-1 developed vesicles, they were fewer and developed much later. In another group inoculated with $5 \times 10^{10} \mathrm{CFU}$ of $\mathrm{p} 3 \mathrm{D}$ NT56/S. cho, none of the animals were protected (Fig. 3E), but animal 7-1 showed delayed disease onset and milder disease than the control animals.

Serum samples were collected at 0,7 , and $14 \mathrm{dpc}$ and tested for the presence of neutralizing antibodies and antibodies against viral NS protein $3 \mathrm{ABC}$ of FMDV. No animals had marked FMDV-specific antibodies at $0 \mathrm{dpc}$, including anti-3ABC antibodies (Tab. II). Animals in the control groups treated with saline, $S$. cho or $\mathrm{pLacZ} / S$. cho developed a high neutralizing antibody response at 7 and $14 \mathrm{dpc}$, suggesting that these animals were exposed to a very large amount of FMDV (Tab. II). A very low neutralizing antibody response was detected at $7 \mathrm{dpc}$ in animals (2-7, 5-6, 3-3, 1-1, 7-1 and 1-34) that were inoculated with $\mathrm{p} 3 \mathrm{D}-\mathrm{NT} 56 / \mathrm{S}$. cho, suggesting that these animals effectively suppressed virus replication. A key distinguishing feature of infected animals is the induction of antibodies against the polyprotein $3 \mathrm{ABC}$ of FMDV [45]. Using an LPB-ELISA, we showed that the animals developing FMD had significantly higher levels of antibodies against $3 \mathrm{ABC}$ as compared to the disease-free animals (Tab. II). These results of serological analysis were consistent with the observation of clinical signs.

\section{DISCUSSION}

Strategies aimed at conferring rapid and efficient protection against FMDV have to face one main challenging factor: the rapid, acute infection caused by this virus, which makes the absence of sufficient amounts of antibodies or other interfering factors essential for protection. The traditional emergency vaccines based on virus inactivation could be effective in preventing disease within 4 to 5 days post-vaccination, due to a critical role for innate immune defenses $[2,39]$. However, signs of disease can appear as early as 2 days post-exposure. Thus, it is necessary to develop antiviral strategies capable of inducing early protection in the face of an outbreak that threatens to spread widely. Recently, we and several other groups demonstrated that RNAi can be potentially used as a therapeutic 

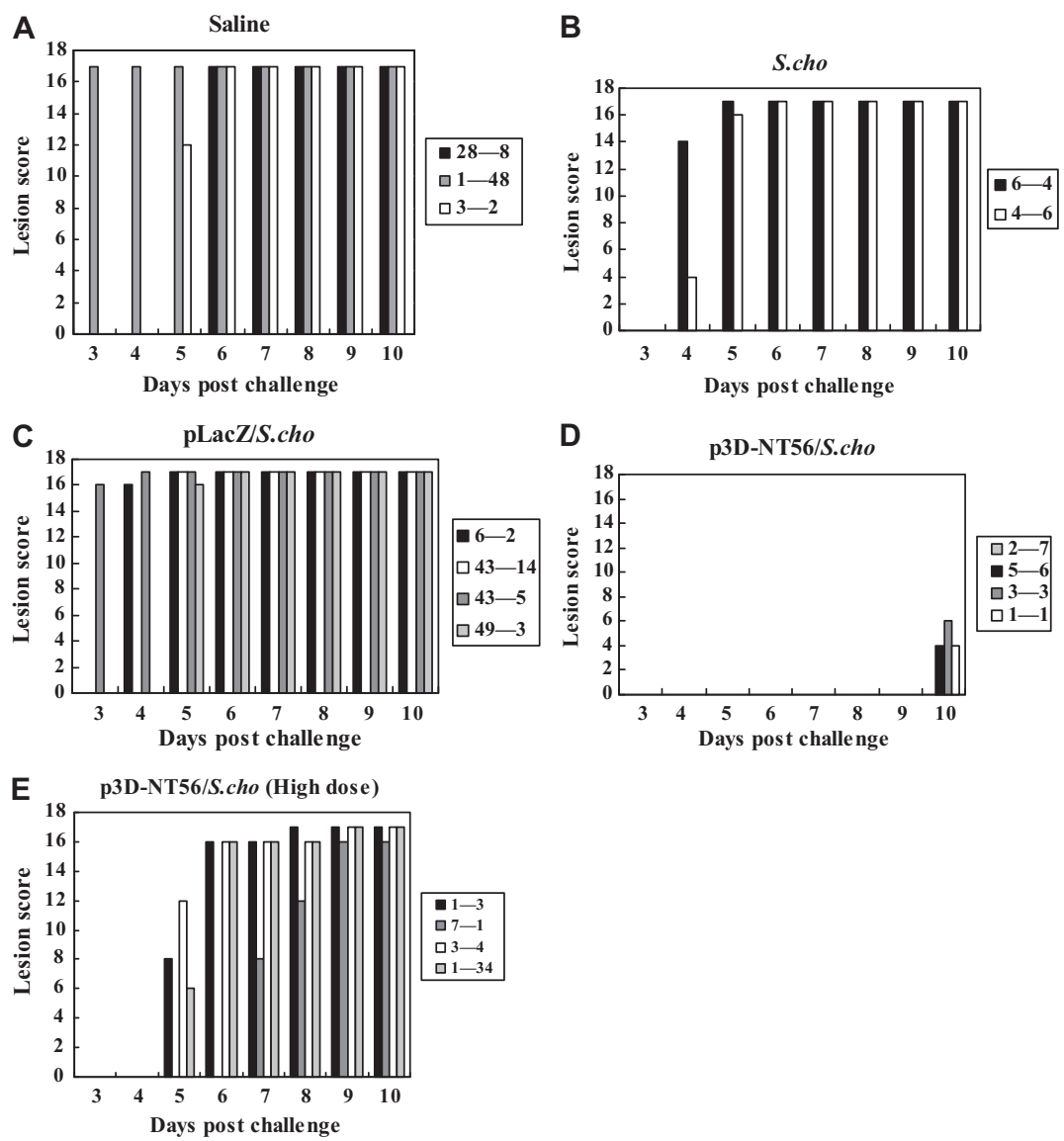

Figure 3. Antiviral activity of $\mathrm{r} S$. cho in swine. Animals were treated with saline (A), S. cho (B), pLacZ/ S. cho (C), p3D-NT56/S. cho (D), or a high dose of p3D-NT56/S. cho (E) and challenged as described in the Materials and Methods section. After challenge, lesion scores were assigned to the animals according to the number of digits plus mouth with vesicles.

or prophylactic mechanism against FMDV $[6,24,33]$. However, to be effective against RNA viruses such as FMDV, which are highly antigenically variable, the siRNA must be targeted to conserved regions. Here, we provide evidence that siRNA targeted to conserved regions of the FMDV genome could effectively inhibit the virus replication of multiple FMDV serotypes.

In this study, three genes, namely 3D, VP4 and $2 \mathrm{~B}$, were selected as targets for three reasons. First, it is well known that different siRNA have different efficiencies in inducing RNAi [21-23]. Second, the proteins encoded by these genes have essential functions in different phases of the viral replication cycle. The RNA-dependent RNA polymerase (3D) is a key enzyme in viral RNA replication $[34,44]$; VP4 is a structural protein, located inside the mature virus particle, and is involved in conversion of provirions to mature virions [1]; and 2B is involved in membrane rearrangements required for viral RNA replication and capsid assembly [19]. Third, we compared 14 reported FMDV isolates of serotype $\mathrm{O}$ and serotype Asia I. The analysis showed that the sequences in these regions are relatively conserved between different FMDV serotypes. 
Table II. Serological analysis of sera from swine inoculated with rS. cho.

\begin{tabular}{|c|c|c|c|c|c|c|c|}
\hline \multirow[t]{2}{*}{ Group } & \multirow[t]{2}{*}{ Animal no. } & \multicolumn{3}{|c|}{ Neutralizing antibody ${ }^{a}$} & \multicolumn{3}{|c|}{$\begin{array}{l}\text { Mean \% inhibition of antibody against } \\
\qquad 3 \mathrm{ABC}^{\mathrm{b}} \pm \mathrm{SD}\end{array}$} \\
\hline & & Day 0 & Day 7 & Day 14 & Day 0 & Day 7 & Day 14 \\
\hline Saline & $\begin{array}{c}28-8 \\
1-48 \\
3-2\end{array}$ & $\begin{array}{l}\leq 3 \\
\leq 3 \\
\leq 3\end{array}$ & $\begin{array}{l}108 \\
362 \\
128\end{array}$ & $\begin{array}{l}362 \\
362 \\
362\end{array}$ & $\begin{array}{c}\mathrm{ND}^{\mathrm{c}} \\
\mathrm{ND} \\
2.6 \pm 0.2\end{array}$ & $\begin{array}{c}\text { ND } \\
\text { ND } \\
39.5 \pm 0.1\end{array}$ & $\begin{array}{c}\text { ND } \\
\text { ND } \\
36.2 \pm 2.0\end{array}$ \\
\hline S. cho & $\begin{array}{l}6-4 \\
4-6\end{array}$ & $\begin{array}{l}\leq 3 \\
\leq 3\end{array}$ & $\begin{array}{l}362 \\
180\end{array}$ & $\begin{array}{l}362 \\
362\end{array}$ & $\begin{array}{l}12.9 \pm 2.9 \\
13.6 \pm 1.9\end{array}$ & $\begin{array}{l}42.9 \pm 1.1 \\
54.5 \pm 1.9\end{array}$ & $\begin{array}{l}55.9 \pm 1.1 \\
63.2 \pm 0.7\end{array}$ \\
\hline pLacZ/S. cho & $\begin{array}{c}6-2 \\
43-14 \\
43-5 \\
49-3\end{array}$ & $\begin{array}{l}\leq 3 \\
\leq 3 \\
\leq 3 \\
\leq 3\end{array}$ & $\begin{array}{l}180 \\
180 \\
256 \\
128\end{array}$ & $\begin{array}{l}362 \\
362 \\
256 \\
180\end{array}$ & $\begin{array}{l}\text { ND } \\
\text { ND } \\
\text { ND } \\
\text { ND }\end{array}$ & $\begin{array}{l}\text { ND } \\
\text { ND } \\
\text { ND } \\
\text { ND }\end{array}$ & $\begin{array}{l}\text { ND } \\
\text { ND } \\
\text { ND } \\
\text { ND }\end{array}$ \\
\hline p3D-NT56/S. cho & $\begin{array}{l}2-7 \\
5-6 \\
3-3 \\
1-1\end{array}$ & $\begin{array}{l}\leq 3 \\
\leq 3 \\
\leq 3 \\
\leq 3\end{array}$ & $\begin{array}{l}23 \\
12 \\
12 \\
23\end{array}$ & $\begin{array}{l}180 \\
180 \\
180 \\
180\end{array}$ & $\begin{array}{c}12.16 \pm 1.1 \\
6.5 \pm 1.0 \\
12.8 \pm 0.8 \\
11.9 \pm 0.5\end{array}$ & $\begin{array}{c}12.6 \pm 2.4 \\
10.1 \pm 0.3 \\
9.5 \pm 0.2 \\
21.2 \pm 3.8\end{array}$ & $\begin{array}{l}25.8 \pm 0.4 \\
27.8 \pm 4.2 \\
32.9 \pm 5.2 \\
29.5 \pm 2.7\end{array}$ \\
\hline p3D-NT56/S. cho ${ }^{\mathrm{d}}$ & $\begin{array}{c}1-3 \\
7-1 \\
3-4 \\
1-34\end{array}$ & $\begin{array}{l}\leq 3 \\
\leq 3 \\
\leq 3 \\
\leq 3\end{array}$ & $\begin{array}{c}108 \\
23 \\
108 \\
64\end{array}$ & $\begin{array}{l}128 \\
180 \\
180 \\
180\end{array}$ & $\begin{array}{c}3.1 \pm 1.0 \\
6.4 \pm 0.0 \\
7.4 \pm 0.7 \\
\text { ND }\end{array}$ & $\begin{aligned} & 36.5 \pm 1.2 \\
& 27.9 \pm 0.2 \\
& 39.1 \pm 1.8 \\
& \text { ND }\end{aligned}$ & $\begin{array}{c}50.0 \pm 4.3 \\
33.6 \pm 3.2 \\
45.5 \pm 0.2 \\
\text { ND }\end{array}$ \\
\hline
\end{tabular}

\footnotetext{
${ }^{a}$ Highest dilution that resulted in a $50 \%$ reduction in the number of $\mathrm{HKN} / 2002$ plaques.

${ }^{\mathrm{b}}$ Mean percent inhibition of the optical density as determined by ELISA.

${ }^{\mathrm{c}} \mathrm{ND}$ : not determined.

${ }^{\mathrm{d}}$ Inoculation with a high dose of $\mathrm{r} S$. cho.
}

Previously, De los Santos et al. [11] found that an siRNA directed against a conserved sequence within the coding region of viral NS protein 2B of FMDV was capable of inhibiting virus replication in infected porcine cells by approximately $97-98 \%$. And this 2B-specific siRNA reduced virus yield in cells infected with 4 different FMDV serotypes. Liu et al. [28] demonstrated that siRNA directed to the conserved regions of the FMDV genome, namely VP4 and 3D, could inhibit the replication of both FMDV strains, serotype $\mathrm{O}$ and Asia I. Our study indicates that p3D-NT56 and p2BNT25 dramatically inhibited viral replication in cultured cells that were susceptible to FMDV of either serotype O or serotype Asia I. Suckling mice treated with the siRNA-expressing plasmids had significantly reduced susceptibility to both serotype $\mathrm{O}$ and serotype Asia I of FMDV.
Efficient delivery of siRNA into cells or organs in vivo remains a major bottleneck in antiviral therapy. A number of methods for delivering siRNA in vivo have been tested $[3,15,27,49]$. Liposome formulations are generally used $[3,15,49]$, but a simple intranasal administration of naked siRNA has been shown to be effective against respiratory viruses [3]. Chen et al. [6] used adenoviruses as the vectors for the delivery of duplex RNA to the target tissue, and total RNA were extracted from five tissues (oropharynx, lung, liver, muscle, and epidermis of the foot) of guinea pigs treated with rAd5 and assayed for rAd5 GFP mRNA. The vast majority of rAd5 was found in the liver. In cloven-hoofed animals, the oropharynx has been identified as the major site of FMDV replication during acute and persistent infection [37]. Brown et al. [4] indicated that the FMDV RNA was localized in the tonsil, pharynx and 
the tracheo-bronchial lymph node. The different tissue distribution of rAd5 and FMDV is probably related to antiviral activity of rAd5 in vivo. Our overall goal was to find a siRNA vector that can spread through the similar infection and transmission tract as FMDV. Attenuated Salmonella has become popular for expressing foreign antigens as a vaccine strain or as a delivery vector of DNA vaccines [10, 12]. Gray et al. [18] found that $S$. choleraesuis was most often recovered from the lymph node, tonsil, lung and alimentary tract of swine inoculated with $S$. choleraesuis. These studies aroused our interest in evaluating the potential of Salmonella as a vector for siRNA delivery. We found that $80 \%$ of guinea pigs were completely protected when inoculated with $10^{9} \mathrm{CFU}$ of p3D-NT56/rS. cho, and that $\mathrm{rS}$. cho also conferred marked antiviral activity in swine. Surprisingly, the antiviral potential of RNAi was evidently impaired in animals treated with a high dose of $\mathrm{rS}$. cho. Srinivasan et al. [43] demonstrated that variation in the initial dose of infection with Salmonella had a profound effect on the response of Salmonella flagellin-specific CD4 T cells in vivo, and that low-dose infection could evade Salmonella flagellin-specific T cell activation completely. Mercado et al. [32] reported that a 25 -fold dilution in bacterial challenge dose did not significantly alter the size or kinetics of the Listeria $\mathrm{LLO}_{91-99}$-specific CD8 $\mathrm{T}$ cell response. The low-dose effect may represent a general mechanism to increase virulence. The immune evasion could probably make the lower dose salmonella more efficient as a vector to carry siRNA.

Because Ad5 lacking E1A and E1B had been used for delivery of RNAi by several groups [6, 40, 48], we evaluated the antiviral potential of combination inoculations of $\mathrm{rS}$. cho and rAd5 in guinea pigs. The results indicate that no significant increase in antiviral effect was achieved in the group treated with the p3D-NT56/S. cho+Ad5-POL mixture, as compared to the group treated with p3D-NT56/S. cho alone. Kim et al. [25] attempted to improve the antiviral effect by use of a mixture of two adenovirus constructs, by giving two injections of shRNA prior to FMDV challenge and by giving injections after FMDV challenge. The high survival rate was maintained by treatment with adenoviruses post-challenge. These results could encourage us to seek more efficient methods of treatment.

In conclusion, a licensed strain of $S$. choleraesuis has a potential as an RNAi delivery system. This strain is very safe for swine, relatively inexpensive to manufacture and well suited for large-scale administration. However, it remains unclear the attenuated Salmonella how to deliver siRNA in vivo. Future studies relevant to cytokine and distribution of siRNA are necessary to examine this issue in more detail.

Acknowledgements. We thank Peng Hao, Xuecen Xie, Lijun Wang, Yanhong Zhang, Yanqi Sun and Tailiang Sun for technical assistance. This work was supported by High-Tech Projects both of 2008ZX08006-001 and 2008ZX08007-004 to Z. Zheng and W. Yan.

\section{REFERENCES}

[1] Bachrach H.L., Foot-and-mouth disease virus, Annu. Rev. Microbiol. (1968) 22:201-244.

[2] Barnett P.V., Carabin H., A review of emergency foot-and-mouth disease (FMD) vaccines, Vaccine (2002) 20:1505-1514.

[3] Bitko V., Musiyenko A., Shulyayeva O., Barik S., Inhibition of respiratory viruses by nasally administered siRNA, Nat. Med. (2005) 11:50-55.

[4] Brown C.C., Piccone M.E., Mason P.W., McKenna T.S.-C., Grubman M.J., Pathogenesis of wild-type and leaderless foot-and-mouth disease virus in cattle, J. Virol. (1996) 70:5638-5641.

[5] Chen W., Yan W., Du Q., Fei L., Liu M., Ni Z., et al., RNA interference targeting VP1 inhibits footand-mouth disease virus replication in BHK-21 cells and suckling mice, J. Virol. (2004) 78:6900-6907.

[6] Chen W., Liu M., Jiao Y., Yan W., Wei X., Chen J., et al., Adenovirus-mediated RNA interference against foot-and-mouth disease virus infection both in vitro and in vivo, J. Virol. (2006) 80:3559-3566.

[7] Chenard G., Miedema K., Moonen P., Schrijver R.S., Dekker A., A solid-phase blocking ELISA for detection of type $\mathrm{O}$ foot-and-mouth disease virus antibodies suitable for mass serology, J. Virol. Methods (2003) 107:89-98.

[8] Curtiss R.T., Hassan J.O., Herr J., Kelly S.M., Levine M., Mahairas G.G., et al., Nonrecombinant and 
recombinant avirulent Salmonella vaccine, in: Talwar G.P., Rao K.V.S., Chauhan V.S. (Eds.), Recombinant and synthetic vaccines, Norosa Publishing House, New Delhi, India, 1994, pp. 340-351.

[9] Darji A., Guzman C.A., Gerstel B., Wachholz P., Timmis K.N., Wehland J., et al., Oral somatic transgene vaccination using attenuated S. typhimurium, Cell (1997) 91:765-775.

[10] Darji A., Lage S.Z., Garbe A.I., Chakraborty T., Weiss S., Oral delivery of DNA vaccines using attenuated Salmonella typhimurium as carrier, FEMS Immunol. Med. Microbiol. (2000) 27:341-349.

[11] De los Santos T., Wu Q., de Avila Botton S., Grubman M.J., Short hairpin RNA targeted to the highly conserved $2 \mathrm{~B}$ nonstructural protein coding region inhibits replication of multiple serotypes of foot-and-mouth disease virus, Virology (2005) 335:222-231.

[12] Dietrich G., Gentschev I., Hess J., Ulmer J.B., Kaufmann S.H.E., Goebel W., Delivery of DNA vaccines by attenuated intracellular bacteria, Trends Immunol. Today (1999) 20:251-253.

[13] Fang X.W., Li Y.L., Huang C.B., Zheng M., Feng W.D., Sun W., Live vaccine against swine paratyphoid from the attenuated smooth strain C500 of Salmonella choleraesuis, Acta Veterinaria Zootechnica Sinica (1981) 12:99-106.

[14] Fountaine T.M., Wood M.J.A., Wade-Martins R., Delivering RNA interference to the mammalian brain, Curr. Gene Ther. (2005) 5:399-410.

[15] Geisbert T.W., Hensley L.E., Kagan E., Yu E.Z., Geisbert J.B., Daddario-DiCaprio K., et al., Post exposure protection of guinea pigs against a lethal Ebola virus challenge is conferred by RNA interference, J. Infect. Dis. (2006) 193:1650-1657.

[16] Gitlin L., Karelsky S., Andino R., Short interfering RNA confers intracellular antiviral immunity in human cells, Nature (2002) 418:430-434.

[17] Gitlin L., Andino R., Nucleic acid-based immune system: the antiviral potential of mammalian RNA silencing, J. Virol. (2003) 77:7159-7165.

[18] Gray J., Fedorka-Cray P., Stabel T., Ackermann M., Influence of inoculation route on the carrier state of Salmonella choleraesuis in swine, Vet. Microbiol. (1995) 47:43-59.

[19] Grubman M.J., Baxt B., Foot-and-mouth disease, Clin. Microbiol. Rev. (2004) 17:465-493.

[20] Grubman M.J., de los Santos T., Rapid control of foot-and-mouth disease outbreaks: is RNAi a possible solution?, Trends Immunol. (2005) 26:65-68.
[21] Hohjoh H., RNA interference (RNA (i)) induction with various types of synthetic oligonucleotide duplexes in cultured human cells, FEBS Lett. (2002) 521:195-199.

[22] Hohjoh H., Enhancement of RNAi activity by improved siRNA duplexes, FEBS Lett. (2004) 557:193-198.

[23] Holen T., Amarzguioui M., Wiiger M.T., Babaie E., Prydz H., Positional effects of short interfering RNAs targeting the human coagulation trigger tissue factor, Nucleic Acids Res. (2002) 30:1757-1766.

[24] Kahana R., Kuznetzova L., Rogel A., Shemesh M., Hai D., Yadin H., Stram Y., Inhibition of foot-andmouth disease virus replication by small interfering RNA, J. Gen. Virol. (2004) 85:3213-3217.

[25] Kim S., Lee K., Park J., Ko Y., Joo Y., Kim H., Park J., Therapeutic application of RNA interference against foot-and-mouth disease virus in vitro and in vivo, Antiviral. Res. (2008) 80:178-184.

[26] King A.M., Underwood B.O., McCahon D., Newman J.W., Brown F., Biochemical identification of viruses causing the 1981 outbreaks of foot-and-mouth disease in the UK, Nature (1981) 293:479-480.

[27] Li B.J., Tang Q., Cheng D., Qin C., Xie F.Y., Wei Q., et al., Using siRNA in prophylactic and therapeutic regimens against SARS coronavirus in Rhesus macaque, Nat. Med. (2005) 11:944-951.

[28] Liu M., Chen W., Ni Z., Yan W., Fei L., Jiao Y., et al., Cross-inhibition to heterologous foot-and-mouth disease virus infection induced by RNA interference targeting the conserved regions of viral genome, Virology (2005) 336:51-59.

[29] Liu M., Niu X., Yan J., Yan W., Zheng Z., Immure response induced by oral DNA vaccination against FMDV delivered by attenuated Salmonella choleraesuis C500, Front. Biol. China (2006) 2:110 114.

[30] Lu S., Cullen B.R., Adenovirus VA1 noncoding RNA can inhibit small interfering RNA and microRNA biogenesis, J. Virol. (2004) 78:12868-12876.

[31] Mason P.W., Piccone M.E., Mckenna T.S., Chinsangaram J., Grubman M.J., Evaluation of a live-attenuated foot-and-mouth disease virus as a vaccine candidate, Virology (1997) 227:96-102.

[32] Mercado R., Vijh S., Allen S.E., Kerksiek K., Pilip I.M., Pamer E.G., Early programming of T cell populations responding to bacterial infection, J. Immunol. (2000) 165:6833-6839.

[33] Mohapatra J.K., Sanyal A., Hemadri D., Tosh C., Kumar R.M., Bandyopadhyay S.K., Evaluation of 
in vitro inhibitory potential of small interfering RNAs directed against various regions of foot-and-mouth disease virus genome, Biochem. Biophys. Res. Commun. (2005) 329:1133-1138.

[34] O'Reilly E.K., Kao C.C., Analysis of RNAdependent RNA polymerase structure and function as guided by known polymerase structures and computer predictions of secondary structure, Virology (1998) 252:287-303

[35] Paglia P., Medina E., Arioli I., Guzman C.A., Colombo M.P., Gene transfer in dendritic cells induced by oral DNA vaccination with Salmonella typhimurium results in protective immunity against a murine fibrosarcoma, Blood (1998) 92:3172-3176.

[36] Pereira H.G., Foot-and-mouth disease, in: Gibbs E.P.J. (Ed.), Virus diseases of food animals, Academic Press, Inc., San Diego, California, 1981, pp. 333-363.

[37] Prato Murphy M.L., Meyer R.F., Mebus C., Schudel A.A., Rodriguez M., Analysis of sites of FMDV persistence in carrier cattle via the polymerase chain reaction, Arch. Virol. (1994) 136:299-307.

[38] Reed L.J., Muench H.A., A simple method of estimating fifty percent end points, Am. J. Hyg. (1938) 27:493-497.

[39] Rigden R.C., Carrasco C.P., Barnett P.V., Summerfield A., McCullough K.C., Innate immune responses following emergency vaccination against foot-and-mouth disease virus in pigs, Vaccine (2003) 21:1466-1477.

[40] Shen C., Buck A.K., Liu X., Winkler M., Reske S.N., Gene silencing by adenovirus-delivered siRNA, FEBS Lett. (2003) 539:111-114.

[41] Shiau A.L., Chen Y.L., Liao C.Y., Huang Y.S., Wu C.L., Prothymosin enhances protective immune responses induced by oral DNA vaccination against pseudorabies delivered by Salmonella choleraesuis, Vaccine (2001) 19:3947-3956.

[42] Song E., Lee S.K., Dykxhoorn D.M., Novina C., Zhang D., Crawford K., et al., Sustained small interfering RNA-mediated human immunodeficiency virus type 1 inhibition in primary macrophages, J. Virol. (2003) 77:7174-7181.

[43] Srinivasan A., Foley J., Ravindran R., McSorley S.J., Low-dose Salmonella infection evades activation of flagellin-specific CD4 T cells, J. Immunol. (2004) 173:4091-4099.

[44] Steitz T.A., A mechanism for all polymerases, Nature (1998) 391:231-232.

[45] Sun T., Lu P., Wang X., Localization of infection-related epitopes on the nonstructural protein $3 \mathrm{ABC}$ of foot-and-mouth disease virus and the application of tandem epitopes, J. Virol. Methods (2004) 119:79-86.

[46] Ter Brake O., Konstantinova P., Ceylan M., Berkhout B., Silencing of HIV-1 with RNA interference: a multiple shRNA approach, Mol. Ther. (2006) 14:883-892.

[47] Woo P., Wong L., Zheng B., Yuen K., Unique immunogenicity of hepatitis B virus DNA vaccine presented by live-attenuated Salmonella typhimurium, Vaccine (2001) 19:2945-2954.

[48] Zhao L.J., Jian H., Zhu H., Specific gene inhibition by adenovirus-mediated expression of small interfering RNA, Gene (2003) 316:137-141.

[49] Zimmermann T.S., Lee A.C.H., Akinc A., Bramlage B., Bumcrot D., Fedoruk M.N., et al., RNAi-mediated gene silencing in non-human primates, Nature (2006) 441:111-114. 